\title{
Cultural Connotation and Product Mapping of Health Tourism in China
}

\author{
Lina Zhong1,2, Baolin Deng1,2 \\ ${ }^{1}$ School of Tourism Sciences, Beijing International Studies University, Beijing, China \\ ${ }^{2}$ Institute for Big Data Research in Tourism, Beijing International Studies University, Beijing, China \\ Email: zhonglina@bisu.edu.cn,dengbaolin0225@163.com
}

How to cite this paper: Zhong, L.N. and Deng, B.L. (2019) Cultural Connotation and Product Mapping of Health Tourism in China. Journal of Service Science and Management, 12, 810-820.

https://doi.org/10.4236/jssm.2019.127055

Received: October 9, 2019

Accepted: December 2, 2019

Published: December 5, 2019

Copyright $\odot 2019$ by author(s) and Scientific Research Publishing Inc. This work is licensed under the Creative Commons Attribution International License (CC BY 4.0).

http://creativecommons.org/licenses/by/4.0/

(c) (i) Open Access

\begin{abstract}
Health tourism products have become the object of tourists' pursuit, and health tourism has become an important project for the development of domestic tourist attractions. Health tourism has the basic projects of traditional tourism. On this basis, it has added many concepts of traditional health culture and formed a new type of tourism that integrates various functions such as recuperation, leisure, health care and vacation. On the basis of expounding the relevant theories of health tourism culture, this paper discusses the connotation of traditional health culture from the perspectives of Taoism, Confucianism and Buddhism, and analyzes the characteristics and classification of Chinese health tourism. The product mapping of traditional health culture in modern health-preserving scenic areas is deeply analyzed with three scenic spots of Wudang Mountain, Shennongjia and Dalaoling, on this basis, to explore the development strategies of traditional health culture and modern tourism development in China.
\end{abstract}

\section{Keywords}

Health Tourism, Traditional Health Culture, Health Tourism Products, Product Mapping

\section{Introduction}

\subsection{The Global Development Trend of Health Tourism}

Health tourism originated in the United States in the 1930s in New Mexico, and has attracted the attention of leisure travel researchers around the world. Modern health tourism aims to maintain health and repair health, and features fitness activities and medical care programs to meet the purpose of relaxing and rejuvenating [1]. With the increase in the number of elderly people, the propor- 
tion of sub-health population has increased, and the world's diseases have continued to grow. Health tourism has developed rapidly in the $21^{\text {st }}$ century [2], especially in France, Hungary, Austria and other countries. Countries such as India, Thailand and Japan have won the favor of health tourists by virtue of their price advantage and special health tourism products.

\subsection{The Significance of Health Tourism Development in China}

China has rich traditional cultural content. Health tourism needs to be built on the traditional health culture. The development of health tourism and health tourism products will further promote the traditional health culture. For health tourism to develop further, it is necessary to test and produce special products that can attract tourists, and many health care methods that have been handed down in traditional health culture have become the core content of health tourism products. In the spirit of "going to its dregs and taking its essence", it discriminates and selects traditional methods of health preservation, combines traditional health culture with modern health care concepts, and develops and innovates health tourism products according to modern human body conditions and health care concepts. Promoting the development of health tourism is of great significance.

\section{Literature Review on Health Tourism}

\subsection{Theoretical Research on Health Care}

\subsection{1. "Health" in Western Culture}

The famous European and American physiotherapist Halbert L. Dunn first proposed the health in Western culture - "Wellness", which means health and happiness [3]. Halbert L. Dunn believes that the highest state of health is self-abundance [4] [5]. Adams believes that health care has the characteristics of multi-dimensionality and multi-space, and that the key to health care is maintenance and health care, focusing on a balance within the human body, and that health has certain relativity, subjectivity and perception [6]. Therefore, health tourism is universally acknowledged as traveling to promote, stabilize, and recover the body, mind, and social well-being [7] [8].

\subsection{2. "Health" in Chinese Traditional Culture}

Zhuangzi first proposed China's "health", and repeatedly emphasized in the "Zhuangzi Health Master" that human health needs to follow the laws of nature and carry out physical and mental maintenance without violating the laws of nature [9]. In traditional culture, "health" is called "receiving", "daosheng", "nurturing", "health", etc. [10]. It is not difficult to see from these words that health in traditional culture refers to feeding, according to life. The law of development is to maintain life, healthy spirit, enhance wisdom, and prolong life.

\subsection{The Connotation of Traditional Health Culture}

The Taoist concept of health care is that the Taoist can learn and fly into a fairy. 
The pursuit is that immortality is not old, the cultivation direction of "Tao" is flying into a fairy, and the pursuit of "Xian" is immortal [11]. Therefore, if you want to cultivate the immortal, you must first maintain your health. It is an important way to improve your health. The monks have accumulated rich experience in constant practice and formed a complex health system. The immortal doctrine, the Lao Zhuang Taoist thought, the Yin and Yang Five Elements theory, and Chinese medicine are all regarded as important sources of Taoist health care. The four books of Confucian classics are the ideological roots of Confucian health culture [12]. Confucianism believes that life must be understood in the world, and if the Son of Man does not understand medicine, it is considered filial. The large number of Confucian doctors fully confirms this point, and "heart-based" is the Confucian philosophy of health. Confucian adherence to the way of health is formed through a combination of physical activities such as exercise, activity and bones, and moral activities. The purpose of this is not only to ask people to be healthy, but also to be more important in mental health. It regards human life as a whole of form, spirit and heart.

Buddhism health pays attention to life and death, and becomes a Buddha. Under the influence of this kind of thinking, human life is often neglected. Buddhism cannot clearly propose specific ways to maintain health, but Changsheng is obviously not listed [13]. Buddhism defines martial arts, meditation, and wisdom as the concept of health, in which the ring is vegetarian, the meditation is meditation, and the qigong and martial arts are returned.

\subsection{Category for Health and Culture Tourism}

Professor Zhang Yuexi once pointed out in the concept and development of health and culture tourism that health tourism is a comprehensive integrated tourism that is dominated by health and culture and can continue to be integrated with nature [14]. Under the guidance of this definition, the scope of health and culture tourism includes health and physical therapy, physical health, spiritual relaxation, hedonic experience, aesthetic psychology, philosophical psychology, ideological meditation, food supplements. It can be seen from the above that the content of the health culture rate is the tourism activity in the tourist scenic spot, so it is very important to develop the health culture tourism resources in the tourist scenic spot.

In summary, three are three research questions in this paper: first, compared with other countries' health tourism, what are the characteristics of China's health tourism? Second, how to classify Chinese health tourism? Thirdly, what role will Chinese traditional culture play in the development of health tourism? And there are two main research objectives.

1) to systematically understand the internal characteristics and development characteristics of China's health tourism development;

2) to rely on China's traditional excellent culture to empower the development of China's health tourism products, so as to provide reference for improving the 
connotation of health tourism products.

To address the above research gaps, we systematically do some exploration about China's health tourism.

\section{Research Method}

\section{The Basis and Background for the Selection of Case Studies}

The method for case study used in this paper is mainly considered from the research object of this paper and the previous research paradigm. From the research object, Wudang Mountain, Shennongjia and Dalaoleng are important material carriers of traditional Chinese health culture. For example, Wudang Mountain is a model of Chinese Taoist health culture. The traditional health culture spreads for a long time and is very representative. From the perspective of research paradigm, case study is a more appropriate research method to explore traditional Chinese health culture. It can discover the connotation, characteristics and evolution of traditional Chinese health culture through the analysis of typical cases. The background of the case selected in this paper is the origin of traditional Chinese health culture, and is known for its health culture. The three selected cases have different cultural connotations, reflecting the differences in case selection and better inducing traditional health cultural traits. The interaction of the three major traditional health cultures. Wudang Mountain represents the traditional Taoist culture. The health tourism products behind it include Taiji Lake Health, Health Restaurant, Taoist Hospital, etc. Shennongjia represents traditional Confucianism. The most distinctive feature is the Chinese Medicine Museum; Dalaoling is Buddhism. An important carrier of culture, featuring green catering, is in line with the "martial" of Buddhist culture.

\section{Characteristics and Classification of Chinese Health Tourism}

\subsection{Characteristics of China's Health Tourism}

Characteristics 1: Nature of tourists' universality. Health tourism is not a patent for the elderly and patients, and people of all ages can participate in health tourism [15]. In recent years, the proportion of healthy people in health tourism in China is getting higher and higher. Whether it is healthy group or sub-health group, or suffering from patients, they are constantly pursuing a healthy lifestyle. Their high pursuit of physical and mental health reflects strong health purpose.

Characteristics 2: Nature of tourist stickiness. Stickiness refers to the attraction of tourist destinations to tourists. This attraction will result in tourists revisiting. The characteristics of health tourism products in tourist attractions determine the attractiveness of tourists. The characteristics of health tourism products include whether there is a unique ecological environment, diversification of health products, completeness of service facilities and service levels. When these conditions are met, the viscosity of health tourists will be greatly improved.

Characteristics 3: Nature of tourism experience. There is no obvious differ- 
ence in the form of health tourism and ordinary tourism. For example, the hot spring therapy in some scenic spots is not much different from the beach in the ordinary scenic spot, so the experience of health tourism and ordinary tourism There is no difference, and this is also an important reason that can be accepted by the public. Health tourism has a layer of experience more than ordinary tourism, which has become the key to attracting tourists. In order to attract tourists, some scenic spots will make visitors feel fresh and fresh with the new health tourism products, which greatly enhances the experience of tourism.

Characteristics 4: Nature of Scientific and professional. The health tourism activities take the original ecology and the theory of traditional Chinese medicine as the core content, and combine the original ecological tourism content with the scientific Chinese medical law to achieve a good effect. For example, Japanese hot springs are well-maintained by professional technicians at the time of water temperature and hot springs; Sanya's spas are also accompanied by full-time technicians; Wudang Mountain's Taoist health courses also have special guidance. Health tourism has certain local characteristics. After combining traditional cultural content with modern scientific therapy, the scientific professionalism of health tourism is vividly reflected.

Characteristics 5: Nature of education. Health tourism advocates self-cultivation, physical fitness. This is also the embodiment of health tourism education. Health tourism can give visitors a deeper understanding of their physical condition, and they can pursue a healthy lifestyle as a standard of health in their lives and work. Although the education of health tourism cannot be immediately effective, the impact of tourists' subtle influence still exists, and this influence will affect the health concept of tourists to varying degrees.

\subsection{Classification of Chinese Health Tourism}

Classification 1: Health tourism driven by ecological environment. Health tourism pursues the realm of "Heaven and Man", paying attention to the harmonious state between man and nature. Any kind of health tourism products are inseparable from the support of the ecological environment. Under the premise of the ecological environment as a carrier. The person is physically and mentally pleasing, and the health content corresponding to the ecological environment is recommended to the tourists. These health tourism products have certain speciality, non-replicability, health value and certain healing effects.

Classification 2: Traditional health tourism. Traditional health tourism is a special form of health care that combines traditional health culture, health preservation methods and living habits. This traditional health tourism product originates from the birthplace of traditional culture and uses the essence of traditional culture to help tourists get the purpose of health preservation, the content of these traditional cultures and methods is characterized by strong technical and high qualifications.

Classification 3: Spa Tourism. The spa tourism takes water as the basic con- 
dition, cooperates with professional Chinese medicine bath and traditional massage techniques, and assists tourists to eliminate fatigue, relax body and mind, and effectively improve the sub-health symptoms of tourists with the help of yoga and meditation. This type of spa requires high quality water resources and requires an ecological environment that matches it.

Classification 4: Sports tourism. Sports tourism is based on sports. This new type of health-care mode is based on exercise and achieves the ultimate goal of weight loss and fitness through exercise. Health sports health tourism is not the same as ordinary health room sports. Health sports health tourism is carried out under the guidance of professional coaches under the background of specific ecological environment, supported by natural resources such as mountains, rivers, grasslands and forests. A health-care campaign, this type of health tourism program is only suitable for young people who are physically fit.

Classification 5: Beauty tourism. Medical beauty and health tourism mainly takes medical beauty as the core content. The destinations of health tourism are mostly medical institutions, which achieve the effects of beauty and body through professional medical means. Medical beauty and health tourism have higher requirements for the venues and medical technology of health tourism.

\section{Case Study Based on the Mapping between Traditional Chinese Health Care and Modern Health Tourism Product}

\subsection{Development Ideas for Health Tourism Products}

The development ideas of health tourism products are mainly oriented to the tourist attractions. The development ideas refer to the precise functional positioning of the development goals of the tourism products to be developed in the tourist attractions, and the health tourism products under the guidance of development ideas. The development effect is a systematic prediction. There are certain differences in the tourism resources and health media of different health tourism destinations. After systematic analysis and evaluation based on existing tourism resources and health media, determine the development intensity and breadth of tourism health resources to ensure that tourists are here. Being able to get a higher level of experience is the core development idea of health tourism products.

\subsection{Taoist Culture Health - Wudang Mountain}

Wudang Mountain is a famous health tourism base in China. Its geographical environment is superior. There are both Shennongjia virgin forest and Danjiangkou Reservoir. Its rich natural resources have laid a solid foundation for the development of health tourism. Wudang Mountain is a model of Taoist culture health tourism. Because there are a large number of ancient buildings in the scenic area, this part of the ancient buildings is mainly composed of Taoist temples, pavilions and pavilions, and Taoist Xianshan, a civilized Taoist temple at home and abroad. Has become an important classic of civilized overseas. Due to its rich Taoist cultural connotation, Wudang Mountain is known as Taoist 
Xianshan. In the development process of Wudang Mountain health tourism products, we should design corresponding health tourism products around the characteristics of Taoist culture and health preservation. These health tourism products include Tai Chi Lake health care, health restaurant, and medical hospital. Among them, Tai Chi Lake is a health tourism product developed around "water". It is mainly characterized by health spa, which uses spa to help tourists eliminate physical and mental exhaustion and soothe. Pressure to meet their health needs; Health Restaurant follows the Taoist culture's "grain of the valley" to meet the deeper needs of tourists for diet and health, using fungi, soy products, pasta as the basis for cooking, adding health herbs to it. It is made into a medicated diet to promote people's health and longevity; the Taoist Medical Center combines Taoist health culture with Chinese medicine, and employs old Chinese medicine practitioners who have in-depth research on Taoist culture to produce various Chinese patent medicines and Chinese herbal medicines to provide Chinese medicine for tourists. Health activities such as massage.

\subsection{Confucian Culture Health - Shennongjia}

Shennongjia Nature Reserve is rich in forest vegetation and rich in natural landscapes. It is known as the "Chinese herbal medicine kingdom". The important content of Confucianism is to practice medicine. Combining the content of traditional health culture, taking the rich Chinese herbal medicine resources of Shennongjia Nature Reserve as the background, the special tourism of traditional Chinese medicine is regarded as an important health tourism product of Confucian culture. Its health tourism products include sightseeing health tourism, experiential health tourism and medical health tourism. Among them, sightseeing health tourism mainly focuses on natural herb production areas and traditional Chinese medicine plantations; health tourism provides pleasant experience for tourists in tourist attractions. Including visitors to experience Zhang's medical culture, personally taste Chinese medicine, experience acupoint stimulation and many other projects; medical tourism provides medical services as the core content, and the Chinese Medicine Museum provides Chinese medicine decoction pieces, Chinese patent medicines to sold tourists.

\subsection{Buddhist Culture Health - Da Lao Ling}

Pursuit of Buddhism culture health is to detach from life and death, not concerned about the body skin. Da Lao Ling National Forest Park is rich in vegetation, providing people with more opportunities to get close to nature. Visitors can enjoy the purpose of self-cultivation while enjoying the scenery of the mountains. Among them, forest tourism, forest health, special forest souvenirs and local health food and beverage have become the key content of Buddhist culture. Among them, the green food is more in line with the "martial" in the Buddhist culture, that is, vegetarian attention. The Dalaoling Forest area is rich in medicinal plants, wild vegetables, wild fruits, etc., and the wild fruits are used 
as raw materials to retain the original nutrients after technical processing. With the beautiful packaging, they can become the favorite forest health foods for tourists. The theme restaurant, which is mainly based on wild vegetables, can provide seasonal mountain dishes in different seasons. The taste is rich and comprehensive, and it naturally becomes an important buying point for health food and beverage. Pollen health is also an important health tourism product. Pollen has the nourishing effect of communication. It is used in all ages, especially anti-aging, coping with various geriatric diseases. After scientific and technological processing, it retains the original nutrients and becomes A major feature of Dalaoling Health Tourism.

\section{Development Strategy for Chinese Traditional Health Culture and Modern Tourism}

\subsection{The Meaning of the Combination of Tradition and Modernity}

The traditional way of keeping in good health conforms to traditional philosophical thoughts, Chinese medicine culture, religious culture, folk culture and other content. As an important part of traditional culture, after years of development, it has formed its own unique characteristics, ideology and patterns. The traditional way of keeping health is more concerned with health and life, coordination of nature and humanity, and self-cultivation. The further development of the traditional way of keeping health needs to meet the needs of modern people. Therefore, the traditional way of health preservation must be re-emerged as a modern health-care. The modern way of health preservation combines ecology, nutrition, and sports on the basis of traditional health-care concepts. Learning and other aspects of the theory, with the support of modern science and technology, in line with the starting point of meeting the psychological needs of modern people, modern health has become a life concept with the characteristics of the times.

\subsection{Development Strategy}

\subsubsection{Scientific and Rational Planning}

The establishment of health tourism scenic spots is not a one-step process. It is necessary to formulate scientific and rational planning. In the choice of health tourism projects, environmental resources and people's demand for health tourism products should be considered, and the development sequence, development priorities and difficulties should be determined. The scientific evaluation method is used to evaluate the resource conditions and basic conditions of the health tourism development area, and the detailed market research on the characteristics of the health tourism products and the source market is carried out. After precise positioning, the scale of the development of health tourism is finally determined. And timing, and develop effective measures.

\subsubsection{Scientific Screening of Traditional Health Culture}

The traditional health culture also contains the dross and essence. In the choice 
of health tourism products, we should consider the essence of its dregs. The selected health tourism products must be active and motivated, suitable for long-term promotion and development. For example, China's traditional Chinese medicine health tourism involves many remedies recorded in ancient books. Some of these remedies have significant effects, but they are not suitable for most people. Therefore, when choosing these remedies, we must fully consider the universality, and after scientific and technical analysis, it can be put into the market.

\subsubsection{Combination of Traditional Health Culture and Modern Health Technology}

For the further development of health tourism, it is necessary to develop health tourism products according to local conditions and create a brand suitable for health tourism destinations. First of all, we must pay attention to the status of health culture tourism products in the whole tourism scenic spot products, pay attention to the deeper development of products, pay attention to the health culture as the core content, improve the grade of health culture tourism products, and further enhance the attention of tourists to the health culture; It is necessary to pay attention to the issue of visitor participation in the development of health culture tourism products, to increase the participation of tourists, to distinguish the differences between health culture tourism products and other tourism products through experience, and to provide tourists with some eye-catching and cultural products with health culture characteristics. The development of the final health tourism products should be matched with the surrounding tourism resources. The related facilities and layouts involved in the health tourism should be integrated with the surrounding ecological environment [16] [17], so that visitors will not feel awkward when they enjoy the health tourism products.

\section{Conclusion}

This paper uses case study to analyze the development of China's health tourism in detail, and finds the following characteristics of China's health tourism: nature of tourists' universality, nature of tourist stickiness, nature of tourism experience, nature of Scientific, nature of Scientific and professional and nature of education. Secondly, China's health tourism can be classified into five categories: health tourism driven by ecological environment, traditional health tourism, Spa Tourism, Traditional health tourism, Sports tourism and Beauty tourism; finally, in view of the current situation of China's health tourism, this paper puts forward some useful ideas and development strategies for the development of health tourism products.

\section{Acknowledgements}

This article was supported by Beijing Social Science Fund (18JDGLB013); and was partially supported by a research funded by Beijing international studies 
university (LYFZ18A002) and the corresponding author of the paper is Baolin Deng.

\section{Conflicts of Interest}

The authors declare no conflicts of interest regarding the publication of this paper.

\section{References}

[1] Wang, Y. (2008) Comparison of Basic Theories of Health Tourism at Home and Abroad. Research on Technology, Economy and Management, No. 3, 109-110.

[2] Bernstein, N. (2012) Chefs, Butlers, Marble Baths: Hospitals Vie for the Affluent. The New York Times, 22.

[3] Yang, F.S., Li, X., Yan, Y., Zu, Y.T. and Zhang, R.H. (2018) Analysis and Countermeasures of Health Tourism Development in Dali, Yunnan Province. Value Engineering, 37, 170-171.

[4] Dunn, H.L. (1961) High Level Wellness.

[5] Yang, F.S., Yan, Y., Li, X., Zu, Y.T. and Zhang, R.H. (2018) Taking Dali, Yunnan Province as an Example, the Investigation and Analysis of the Development of Health-Preserving Tourism with Ethnic Characteristics in Yunnan Province. Value Engineering, 37, 216-218.

[6] Zhang, Z.L. (2016) Public Analysis of Health Tourism for the Elderly. Journal of Tourism, 31, 10-11.

[7] Kaspar, C. (1996) Gesundheitstourismus im Trend.

[8] Kazemha, A.S. and Dehkordi, K.S. (2017) The Principles of Designing Hospital Hotel with the Approach of Health Tourism in Kish Island. Tarih Kultur Ve Sanat Arastirmal Ari Dergisi Journal of History Culture and Art Research, 6, 515-531. https://doi.org/10.7596/taksad.v6i1.758

[9] Liu, Q.Y. and Lu, N. (2016) Development Strategy of Healthy and Healthy Tourism from the Perspective of Global Tourism. Journal of Tourism, 31, 4-6.

[10] Luo, Y.L., Zhou, L.Q. and Liu, Y.B. (2016) Study on the Construction Path of "Global" New Eco-Countryside: Taking Wuyi Eco-Health Tourism and Beautiful Rural Construction as an Example. Eco-Economy, 32, 139-142.

[11] Wang, J.F. and Yuan, T.X. (2015) Development of Forest Health Tourism Products: Taking Damingshan National Nature Reserve in Guangxi as an Example. Guangxi Forestry Science, 44, 194-199.

[12] Ye, C., Li, Y.-N. and Yao, L. (2014) Classification and Evaluation of Health-Preserving Tourism Resources from the Perspective of Traditional Chinese Medicine Theory: Taking Guizhou Health-Preserving Tourism Resources as an Example. Journal of Hainan Normal University (Natural Science Edition), 27, 449-456.

[13] Dong, X.Y., Zhao, H. and Lai, B.N. (2014) Research on the Development of Health Tourism Products in Zhongnan Mountain Area Based on RMP Analysis. Hubei Agricultural Science, 53, 1976-1979.

[14] Lan, J.P. and Tian, M.W. (2013) Study on the Development Model of Health-Preserving Tourism under the Visual Threshold of Non-Scenic Tourism. Journal of Zhejiang Normal University (Social Science Edition), 38, 71-76.

[15] Liu, T.T., Ma, J.Z. and Zhang, B. (2013) Research on the Development Strategy of 
Health Tourism Products in Forest Parks. Academic Exchange, No. 9, 119-122.

[16] Han, J.S., Lee, T.J. and Ryu, K. (2018) The Promotion of Health Tourism Products for Domestic Tourists. International Journal of Tourism Research, 20, 137-146. https://doi.org/10.1002/jtr.2161

[17] de la Hoz-Correa, A., Muñoz-Leiva, F. and Bakucz, M. (2018) Past Themes and Future Trends in Medical Tourism Research: A Co-Word Analysis. Tourism Management, 65, 200-211. https://doi.org/10.1016/j.tourman.2017.10.001 